\title{
A APLICAÇÃO DA METODOLOGIA TRADICIONALISTA NO ENSINO DE BASE E SUAS CONSEQUÊNCIAS PARA A FORMAÇÃO CRÍTICA E PSICOSSOCIAL
}

\author{
Iana Sara Silva de Alencar ${ }^{1}$
}

RESUMO: A aplicação do Método Tradicionalista se consolida como uma prática mecanicista, onde os recursos holísticos pouco são considerados como alicerces de uma formação social para além do contexto educacional. Já existem escores que indicam o nível de racionalização, aprendizagem e pensamento crítico na relação da tríade que envolve o sistema básico de ensino: família, educando e equipe pedagógica/escolar. Assim, ressaltando a importância de entender o significado de um ensino-aprendizado integracionista, o artigo propõe uma reflexão acerca dos tipos de manifestações psicossociais vivenciadas por um indivíduo que experienciou seus estudos de base a partir do Método Tradicional de Ensino e qual o nível de criticidade alcançado em comparação ao modelo moderno de integração educacional.

Palavras-chave: Método Tradicionalista. Ensino-Aprendizado. Integração Educacional. Manifestações Psicossociais.

ABSTRACT: In this article, the issue of sexual abuse is addressed from the perspective of the victim, relating the event concerned with possible predispositions psychopathological presented the same throughout his life. For this reason, it is essential to consider the significance of the topic, its existential implications, its social representation and exposure (sometimes not formulated) of the victim, to be guided thereby developing psychotherapy when the issue is emerging in the therapeutic setting. The basis for understanding presented here is based on Gestalt Therapy and its nuances, from the correlation of the contact blocks from the sexual abuse reflected during the existence of the once abused psychologically and morally.

Keywords: Hermeneutics. Sexual Abuse. Meaning.Existence. Gestalt Therapy.

\footnotetext{
${ }^{1}$ Doutoranda em Psicologia Clínica pela UNIVERSIDAD DE CIENCIAS EMPRESARIALES Y SOCIALES (UCES) / Buenos Aires, Argentina. Psicóloga pela Faculdade da Amazônia Ocidental (FAAO). Especialista em Docência do Ensino Superior com ênfase em Gestão Escolar (FAAO). Atuação psicossocial (intervenções individuais, familiar, grupal e comunitária; fortalecimento de vínculos socioafetivos e construção de práticas coletivas).Gestalt-terapeuta (CCGT - Belém). Docente (ESTÁCIO UNIMETA Centro Universitário). E-mail: iana.sara.psy@gmail.com.
} 


\section{INTRODUÇÃO}

A escola sempre foi considerada parte integrante e fundamental na obtenção dos conhecimentos necessários para o convívio social, atuando diretamente na vida da maioria das pessoas que a ela tem acesso por longos anos. Desse modo, é importante que o ambiente escolar, incluindo seus valores, filosofia e equipe, atue numa proporção muito mais ampla, contribuindo para o resgate das vivências subjetivas e seus reflexos existenciais.

A questão essencial não se limita ao que está sendo transmitido ao longo das séries e anos, mas, em como este conteúdo é percebido pelos alunos. Há um abismo entre transmissão e ensinamento; decodificação e aprendizado. Por essa razão, faz-se necessário um trabalho que considere todas essas dimensões, inclusive a dificuldade de aprendizagem quer sejam de ordem intelectual, ambiental ou físico-biológica; dentre as quais, a psicologia se faz presente no assessoramento das buscas de causa e auxílio e o direito como norteador dos parâmetros legais para tal.

A proposta está em uma reflexão quanto ao aprendizado didático e sistêmico para as crianças envolvidas, com uma metodologia que atraia a atenção e percepção das mesmas, que, outrora, não conseguiram obter êxito nas questões de aprendizagem através da pedagogia convencional ou por questões de origem orgânica. A verdade é que a escola deve assegurar o acesso inclusive de crianças com dificuldades intelectuais em seu contexto.

Torna-se essencial fomentar a diversidade das práticas educativas, ou seja, é imperativo aumentar a flexibilidade da remediação da prática curricular e dos métodos de ensino na sala de aula, de modo a dar respostas mais cabais as necessidades individuais de cada aluno (FREIRE, 2005).

A partir de tais fatos, faz-se mister que profissionais realizem intervenções de forma a proporcionar melhor e/ou maior qualidade do ensino, auxiliando também no "reaprendizado" das crianças, utilizando recursos pró-ativos que proporcionem avanços também nos aspectos físico (coordenação motora e habilidades sensoriais) e social (relacionamento interpessoal a partir do convívio com outras crianças, tal qual, o cumprimento de regras - auxiliando a compreensão de "deveres e direitos"); assim como buscar recursos para reforçar o desenvolvimento educativo de crianças com dificuldades de aprendizagem e convívio na sala de aula devido a alguma dificuldade psicossocial.

A questão mais intrínseca dos estudiosos favoráveis aos modelos construtivistas refere-se à idéia de que todos os jovens, independentemente da diferença de classe social ou de necessidades especiais de educação, podem fazer mais progressos. O fato é que, nesse contexto, surge o modo como as fronteiras de hierarquia atuam, ainda que, de forma camuflada, no contexto escolar. 
Exemplo disso é a visível diferença entre escola pública e escola privada, o que fragmenta o processo educacional. As queixas escolares, especialmente em escolas públicas são emergentes, suscitando assim, um novo olhar para esse contexto. Seria necessária uma prática voltada a combater o mecanicismo metodológico nas escolas públicas? Há de se indagar os meios utilizados para estimular a motivação dos alunos dessas escolas. Deve-se questionar como a mediação psicossocial pode expandir-se, rumo ao meio que este aluno vive, fazendo-o experienciar a educação repassada na classe para suas atividades cotidianas.

\section{Formação Crítica e Psicossocial: Reflexões Iniciais}

Ainda que a escola pública não disponha de recursos maiores no sentido de proporcionar um espaço/ambiente melhor adaptado, esta deve focalizar outros recursos disponíveis para uma práxis mais humanizada e efetiva. Eis aí a responsabilidade de uma metodologia voltada transpor as atuações repetitivas, rumo à uma prática mais reflexiva, pensando não somente em remover as causas, mas, auxiliar o ambiente escolar à estimulação do papel social que esta representa em sua comunidade.

A partir da perspectiva e implicação reflexiva, pergunta-se: Com quem se aprende? Com o professor. Este, porém, deixa de ser sujeito do processo de ensino e torna-se "apenas um orientador e organizador das situações de ensino". (PIMENTA; ANASTASIOU, 2005). No que se refere à aprendizagem, considera-se também o desenvolvimento cognitivo, idade cronológica e ambiente sócio/familiar do ser que se apresenta para aprender.

Formação Crítica e Psicossocial

Variáveis Dependentes

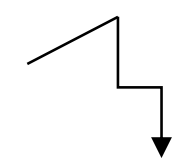

Apresentados na vivência ou decorrentes da maneira como elabora subjetivamente sua existência, a partir do ensino-aprendizado.

O Modelo Tradicional de Ensino

$\underline{\text { Variáveis Independentes }}$

Tipo de elaboração e transmissão educacional.

Nesse sentido, a inclusão de recursos que estimulem a interatividade, criatividade e o humanismo, embasados no método fenomenológico, alcançam um modelo estratégico e direcionado 
não somente aos quesitos lógicos de formação, senão, ao alicerce de vivências subjetivas e interpessoais saudáveis.

Por essa razão, para que o desenvolvimento crítico e psicossocial no âmbito educacional seja efetivo, faz-se indispensável uma análise do cenário em que o aluno (ou a equipe pedagógica envolvida) vive, pois, é lá que estão inseridas as raízes culturais que potencializam seus comportamentos. Dessa forma, será possível uma melhor compreensão do processo de aprendizagem do aluno em questão e, consequentemente, uma intervenção mais efetiva na superação das dificuldades que estes podem apresentar no âmbito escolar.

\section{A integração da família e demais vínculos rumo à produtividade escolar - Um Olhar para a Inclusão}

Quanto à importância da família na escola: Quando pensamos em processo de formação dos alunos não podemos excluir a participação ativa das famílias e, certamente, dos educadores.

Junto com a família, em encontros sistematizados, refletir sobre a função da dificuldade de aprendizagem neste momento do ciclo de vida familiar (Carter \& Mcgoldrick, 1995). Criando estratégias com pais e cuidadores que possibilitem o sucesso escolar da criança.

No Parágrafo único do Capítulo IV do Estatuto da Criança e do Adolescente (BRASIL, 1990), encontramos que "é direito dos pais ou responsáveis ter ciência do processo pedagógico, bem como participar da definição das propostas educacionais", ou seja, trazer as famílias para o convívio escolar já está prescrito no Estatuto da Criança e do Adolescente. Família e escola são pontos de apoio ao ser humano; são sinais de referência existencial. Quanto melhor for a parceria entre ambas, mais significativos serão os resultados na formação do educando. A participação dos pais na educação formal dos filhos deve ser constante e consciente. Vida familiar e vida escolar são simultâneas e complementares.

O bom relacionamento entre esses personagens é fundamental durante o processo de inserção da criança na vida escolar, além de representar a ação conjunta rumo à consolidação de uma pedagogia voltada para a infância.

É incontestável que, desde cedo, essa avaliação pode perder o foco se o professor reduzir tudo à cobrança, se este usar a nota como instrumento de controle e classificar os alunos como "bons ou ruins". Esse nunca foi o objetivo da Avaliação Escolar, mas, ainda hoje há professores que se vangloriam por deter o poder de aprovar ou reprovar. Atitudes assim são decorrentes do descompromisso filosófico por parte de alguns educadores e também do mecanicismo e conformismo que sufoca algumas escolas. 
Em relação às crianças com dificuldades intelectuais, consideradas especiais, embasamo-nos na Declaração de Salamanca: Esta propõe que "as crianças e jovens com necessidades educativas especiais devem ter acesso às escolas regulares, que a elas devem se adequar...", pois tais escolas "constituem os meios mais capazes para combater as atitudes discriminatórias, construindo uma sociedade inclusiva e atingindo a educação para todos...” (UNESCO, 1994, p. 8-9).

De acordo com TURRA Apud LOPES, VEIGA, (2000):

\begin{abstract}
O conteúdo é uma parte integrante da matéria-prima; é o que está contido em um campo de conhecimento. Envolve informações, dados, fatos, conceitos, princípios e generalizações acumuladas pela experiência do homem, em relação a um âmbito ou setor da vida humana (...). Os bens culturais, quando adaptados, elaborados e organizados pedagogicamente compõem os conteúdos programáticos. Estes constituem a fonte de onde o professor seleciona o conjunto de informações que trabalhará com seus alunos.
\end{abstract}

No que diz respeito aos professores: "Investir na formação dos professores é uma tarefa fundamental para se levar a bom termo a atividade docente, atividade cujo grau de exigência é hoje indiscutível, dada a complexidade das situações com que é confrontada, pois assim podem contribuir para a melhoria do sistema de ensino e para que este beneficie todos os alunos, atendendo as necessidades individuais de cada um.

Que tipo de orientação é necessário imprimir a formação de professores para fomentar a mudança? Como podemos ajudar os professores a adotarem uma perspectiva mais ampla das dificuldades educativas? A formação de professores pode contribuir para melhorar as respostas dadas pelos docentes aos sinais que os alunos emitem como reflexo das suas necessidades especiais de educação. (FREIRE, 2005).

Assim, investir na formação dos professores é uma tarefa fundamental para se levar a bom termo a atividade docente, atividade cujo grau de exigência é hoje indiscutível, dada a complexidade das situações com que é confrontada, pois assim podem contribuir para a melhoria do sistema de ensino e para que este beneficie todos os alunos, atendendo as necessidades individuais de cada um. Importa também, não esquecer a diversidade da população escolar, provocada pela nova realidade da escolaridade obrigatória e da democratização ou massificação do ensino. Para isso, é necessário inovar ou renovar as práticas na sala de aula, de forma a tornar mais abrangentes os processos de ensino/aprendizagem (FREIRE, 2005).

Almeida (1993), também considera que a aprendizagem ocorre no vínculo com outra pessoa, a que ensina, "aprender, pois, é aprender com alguém”. É no campo das relações que se estabelecem entre professor e o aluno que se criam às condições para o aprendizado, seja quais forem os objetos de conhecimentos trabalhados. Nesse sentido, faz-se essencial ir além do tradicional, da didática por vezes imposta, mas pouco proveitosa, dos estigmas e comparações; visando cada criança como única e com estímulos únicos para o aprendizado. 


\section{$3 \mathrm{O}$ Resgate da subjetividade no processo de ensino-aprendizagem}

Tratar todas as questões inerentes ao contexto escolar como métodos unicamente voltados para o "ensino quantitativo", nada mais é que, reduzir as diversas funções desta que, socialmente falando, possui a responsabilidade de fornecer bases de ensino que nutram o educando tanto no aspecto físico quanto intelectual.

Percebe-se que apenas uma atuação mobilizadora e direcionada ao resgate do positivo seria necessária para produzir frutos de mudança nesse sentido. Professores que reduzem tudo à cobrança usam a nota como instrumento de controle e classificavam os alunos como "bons ou ruins", atuam em um ciclo de estigmatizas estabelecidos. De fato, isso é recorrente em muitas escolas, o que pode intensificar o número de alunos com déficit no aprendizado.

A educação, para além do Método Tradicionalista, é tecida em conjunto - por alunos e professores - frente aos exercícios da leitura e da escrita, exaustivamente praticadas nas aulas. Assim, mestres e aprendizes atuam juntos na construção do conhecimento, assessorados pela incidência da problemática social mais atual e pelo arsenal de saberes já edificados, patrimônio intransferível do ser humano.

É incontestável que, desde cedo, essa avaliação pode perder o foco se o professor reduzir tudo à cobrança, se este usar a nota como instrumento de controle e classificar os alunos como "bons ou ruins”. Esse nunca foi o objetivo da Avaliação Escolar, mas, ainda hoje há professores que se vangloriam por deter o poder de aprovar ou reprovar. Atitudes assim são decorrentes do descompromisso filosófico por parte de alguns educadores e também do mecanicismo e conformismo que sufoca algumas escolas.

Eis aí um conjunto de informações que testificam valores de diferentes camadas de profissionais da Educação. A verdade é que, os ideais construtivistas seguem frutificando no meio escolar e produzindo sentimentos motivacionais que possibilitam acreditar num ambiente escolar mais humanizado e menos estereotipado. Por outro lado, para os críticos, esse novo modelo educacional impede os métodos de obtenção do conhecimento que nos trouxe até aqui: aquele cumulativo, meritocrático, metódico, organizado em currículos que fornecem um mapa e um plano de vôo para o jovem aprendiz.

Pensar em processo de formação social é realizar uma imediata associação relacionada à integração entre o ser (o homem e sua singularidade) e o mundo (sociedade). Esta interação só é possível a partir das relações construídas no decorrer da existência humana. Assim, dá-se início a um processo constructo de contextos, permitindo que cada ser adquira sua própria visão em relação 
ao mundo, a partir de seus valores (em maioria adquiridos no seio familiar), crenças e subjetividade, ao passo que adquire senso crítico.

\section{Ações psicossociais para o desenvolvimento de práticas interventivas no ambiente escolar}

Sabe-se que para uma educação de sucesso, todas as áreas citadas acima necessitam estar em amplo funcionamento: uma escola motivacional, profissionais preparados e uma didática capaz de envolver absolutamente todos os alunos. No que se refere ao ensino infantil, além destes requisitos, devem ser considerados também o desenvolvimento cognitivo, idade cronológica e ambiente sócio/familiar da criança. As dificuldades de aprendizagem segundo o comitê Nacional de Dificuldades de Aprendizagem (CNDA) (1988, on line), são definidas da seguinte forma: "É um termo genérico que se refere a um grupo heterogêneo de desordens manifestadas por dificuldades significativas na aquisição e utilização, na compreensão auditiva, fala leitura, escrita raciocínio ou habilidades matemáticas [...]”.

A partir de Entrevistas Semi-Estruturada, dirigidas ao corpo docente da instituição e aos pais dos alunos especificados na demanda abordada neste trabalho, este estudo busca, através da validade científica do Método Fenomenológico, uma pesquisa exploratória e descritiva, a fim de identificar os principais processos envolvidos na assimilação educacional de uma instituição escolar.

Deveriam ser priorizadas escolas que atendam apenas o nível fundamental. A seleção da demanda será feita por idade e ano letivo, o que resultará na observação dos alunos em sala de aula e na divisão de atendimentos para os mesmos, para que no tempo proposto a esta práxis, todos sejam alcançados. Assim, alunos de mesma faixa etária, estudantes do mesmo ano letivo e com dificuldades semelhantes, poderiam ser atendidos, algumas vezes, de maneira coletiva. Para tanto, um olhar aprofundado no existencialismo pode ser relevante na compreensão dos aspectos vivenciais do referido contexto. Ribeiro (1997), afirma que, quando empregamos esse método, estamos dizendo:

I. Que vemos a realidade, a observamos com atenção, a descrevemos fielmente e a explicamos de modo cuidadoso (...)

2. Que trabalhamos o aqui - agora. Estamos atentos à temporalidade e à espacialidade na qual a pessoa se movimenta e que se revela na vida como na terapia. Só se tem acesso real à pessoa quando se tem acesso à sua totalidade possível.

3. Que trazemos para o aqui e agora as emoções e sentimentos vividos pelos clientes, porque uma das finalidades da psicoterapia é a recuperação do emocional, é reexperienciar passado e futuro com a força da energia do presente. 
4. Que estamos atentos à pessoa como um todo; ao verbal e ao não-verbal, estamos atentos a um perfume, ao balançar espontâneo e despercebido dos pés, ao estilo da roupa, às mudanças físicas, como um corte de cabelo, o cortar uma barba de longos anos. Tudo, no ser humano, é fecundo de significados. Não é o sintoma que está em terapia, é a pessoa como um todo.

5. Que evitamos interpretações, porque trabalhamos com o sentido imediato das coisas trazido pelo cliente, que deve sempre ser acreditado, mesmo quando as aparências parecem dizer o contrário. A interpretação pode envolver juízos de valor.

6. Que entendemos que o sintoma é apenas a ponta do iceberg e, por isso, trabalhamos prioritariamente com os processos que os mantêm, mais do que com eles em si mesmos. O sintoma implica desvio de uma energia que, originalmente, era saudável. Não podemos não ver o sintoma, mas não podemos ficar parados ali. O sintoma é o lugar onde o trem descarrilou, o lugar de chegada é mais além.

7. Que aceitamos e trabalhamos a experiência imediata do sujeito, porque a consciência nunca é consciência do nada, e, por mais tênues que sejam os sinais, é sempre uma pista que o corpo dá.

8. Que os experimentos são uma riqueza imensa e podem ser de grande valia, quando realizados cuidadosamente.

\section{CONCLUSÃO}

A educação precisa deixar de ser domesticada para ser libertadora. A autenticidade será a principal ferramenta do educador que conduzirá o aluno à aprendizagem significava. Ensinar é mais que transmitir conhecimento - é despertar a curiosidade, é instigar o desejo de ir além do conhecido. É desafiar a pessoa a confiar em si mesmo e dar um novo passo em busca de mais. Ajudados pela Escola a vencer os obstáculos da vida, a automotivação do aluno para o abandono de práticas infratoras e agressivas será bem maior.

Portanto, um trabalho escolar conjunto, unindo uma equipe multidisciplinar ativa, colabora para uma educação de sucesso e para a decadência dos índices de violência escolar. Uma formação voltada para o social, o compromisso filosófico e a criatividade podem reverter um quadro relativamente estagnado a um nível de produtividade, por meio de políticas públicas voltadas à Educação.

Recordar os altos índices de evasão escolar, reprovação, à falta de acesso de muitas crianças aos bancos escolares e ao período diário, considerado extremamente curto - três horas de permanência em sala de aula, é, dentre as muitas causas para tais desajustamentos, o reflexo da escassez de recurso e a inércia governamental, tal qual, da própria sociedade. É necessário focar na essência humana e na 
autenticidade existencial, capaz de promover o crescimento do ser, a partir da ressignificação de suas vivências, pois: "O homem é [...] o único ser que tem a capacidade de cuidar do próprio ser, de se projetar, e é neste sentido que dizemos que ele é o único que existe" (RIBEIRO, 1985, p. 37). Desse modo, as dificuldades apresentadas no sistema educacional são consideradas, mas, não determinantes nesse processo.

Logo, a ideia central do trabalho quanto ao que foi abordado, traduz-se em buscar o coletivo, a coesão cultural e a integração a partir das reflexões sobre a identidade escolar. Para mudar é preciso um processo intenso de conscientização, sobretudo, compreendendo como as políticas sociais e as ideologias dominantes afetam o cotidiano de uma comunidade com a qual a escola tem que lidar tal qual o poder socializador que o sistema educacional possui.

A verdade é que esses ideais apresentados seguem frutificando no meio escolar e produzindo sentimentos motivacionais que possibilitam acreditar num ambiente escolar mais humanizado e menos estereotipado.

As saídas propostas traduzem-se na possibilidade de mestres e aprendizes atuarem juntos na construção do conhecimento, assessorados pela incidência da problemática social ma is atual e pelo arsenal de saberes já edificados, patrimônio intransferível do ser humano. Assim, a Educação poderá ser a forma teórica ampla que reúna as várias tendências atuais do pensamento educacional, assumindo tendências que têm em comum a insatisfação com um sistema educacional que teima (ideologia) em continuar essa forma particular de transmissão que é a Escola, que consiste em fazer repetir, recitar, aprender, ensinar o que já está pronto, em vez de fazer agir, operar, criar, construir a partir da realidade vivida por alunos e professores.

A partir desta análise referente à abrangência das áreas - Escolar e Educacional, torna-se visível a importância de suas nuances e a capacitação da equipe multidisciplinar para a implementação de um modelo holístico na referida atuação. Assim, a colaboração para que um completo estado de bem-estar na Escola seja possível, torna-se ímpar que cada instituição possua um profissional específico de ambas. Para isso, um novo olhar estatal deve ser implantado e formulado, para a inserção de novos profissionais do contexto Escolar e Educacional na Escola.

É necessário reconhecer a importância da afetividade no desenvolvimento infantil como o toque, o carinho e a atenção, melhorando desse modo as relações de interação entre professor e aluno. A escola não tem a finalidade de resolver os problemas sociais. O professor deve estar em constante capacitação e atualização, pois ele tem em suas mãos a tarefa de despertar o gosto do saber, respeitando as diferenças de cada aluno. Nesse sentido conhecer as ferramentas a serem usadas, o método a ser aplicado e de que forma este será aplicado é de suma importância. Estabelecer também 
uma relação saudável, que possa atribuir a devida importância ao trabalho multidisciplinar . Focar todos os aspectos relevantes no desenvolvimento relacional.

\section{REFERÊNCIAS}

ALMEIDA, S.F.C. O lugar da afetividade e o desejo na relação ensinar-aprender; In: Revista Temas em Psicologia. Ribeira Preto - SP: Sociedade brasileira de Psicologia, 1993.

BRASIL, Estatuto da criança e do adolescente - ECA. Brasília, Distrito Federal: Senado, 1990.

FREIRE, José M. A Escola como Observatório de Necessidades Educativas dos Alunos e Formativas dos Professores. [S.I] : [S.n], 2005.

PIMENTA, Selma Garrido; Anastasiou, Léa das Graças Camargos. Docência no Ensino Superior. $2^{a}$. Ed. São Paulo: Cortez, 2005.

RIBEIRO, J. P. Gestalt-Terapia: refazendo um caminho. São Paulo: Summus, 1985.

TURRA, Clodia Maria Godoy, et al. Planejamento de Ensino e Avaliação. Porto Alegre, PUC. EMMA, 1975.

UNESCO. Declaração de Salamanca e Linha de Ação sobre Necessidades Educativas Especiais. Brasília: CORDE, 1994 . 